'Departamento de Dermatología, Facultad de Medicina, Pontificia Universidad Católica de Chile, Santiago, Chile.

'Universidad de Los Andes, Santiago, Chile.

aResidente de Dermatología, Facultad de Medicina, Pontificia Universidad Católica de Chile.

Santiago, Chile.

Los autores no refieren conflicto de intereses.

Recibido el 20 de diciembre de 2014, aceptado el 30 de julio de 2015.

Correspondencia a: Dra. Verónica Vial Letelier Universidad de los Andes, Santiago, Chile. vero.vial.|@gmail.com

\section{Ébola: caracterización, historia y manifestaciones cutáneas; lo que debemos saber}

\author{
MARIANNE KOLBACH ${ }^{1}$, JUAN EDUARDO CARRASCO-ZUBER ${ }^{\mathrm{a}}$, \\ VERÓNICA VIAL-LETELIER ${ }^{2}$
}

\section{Ebola: characterization, history and cutaneous manifestations}

\begin{abstract}
Ebola virus (EV) is one of the most virulent human pathogens. Fruits bats are its natural reservoir, the transmission to humans is across wild animals (especially primates) and the propagation in human populations is through bodily fluid contact. The actual outbreak started in December 2013 and crossed continental borders. Up to now, there are 17,145 suspected and confirmed cases with 6,070 deaths, resulting a total case fatality rate of $35 \%$. Clinical manifestations can be divided in 3 phases. In phase I, symptoms are similar to flu, which may appear in a range of 2 to 21 days. In phase II which occurs in over 50\% of cases, visceral symptoms and mucocutaneous manifestations appear within 4 and 5 days of the onset of symptoms. The main symptoms are a macular or maculopapular non-pruritic rash, desquamation and mucosal involvement of eyes, mouth and pharynx. In phase III, recovery or death occurs. The diagnosis is made on clinical grounds, epidemiological suspicion and a positive polymerase chain reaction (PCR) test. The treatment is supportive. If there is a suspected case, it should be notified immediately and all relevant safety measures should be instituted.

(Rev Med Chile 2015; 143: 1444-1448)
\end{abstract}

Key words: Ebola; Ebola virus; Epidemics; Hemorrahagic fever.

\section{E} 1 virus del Ébola (VE) se encuentra entre los patógenos más virulentos de los seres humanos, causando una enfermedad grave que se asemeja a un shock séptico fulminante.

La tasa de letalidad en la epidemia actual de la enfermedad del VE en África Occidental ha sido estimada en aproximadamente $70 \%{ }^{1}$.

El virus es transmitido al ser humano por animales salvajes y se propaga en las poblaciones humanas por transmisión de persona a persona ${ }^{2}$.

\section{Características}

Es un virus ARN de cadena simple no segmentada de polaridad negativa que pertenece a la familia Filoviridae, esta familia tiene dos géneros el Ébola y el Marburg. El nombre Ébola se debe a un río del noroeste del Congo ${ }^{3}$.

El género Ebolavirus comprende cinco especies distintas: Bundibugyo ebolavirus (BDBV), Reston ebolavirus (RESTV), Sudan ebolavirus (SUDV), TaïForest ebolavirus (TAFV) y Zaire ebolavirus $(\text { ZEBOV })^{4,5}$.

El reservorio natural del VE parece estar en los murciélagos, en especial en la especie Rousettus aegyptiacus. El ciclo del VE en la naturaleza todavía no está claro. Se sabe que afecta a ciertos primates grandes y a los murciélagos. Se asume que los murciélagos son portadores sanos y éstos infectan a los monos. Los seres humanos cazan en el bosque y son contaminados al comer carne de animales silvestres infectados, por contacto con monos o por el consumo de murciélagos ${ }^{6,7}$. Los 
cerdos también pueden infectarse con VE. En Filipinas se ha aislado la cepa Reston en cerdos ${ }^{8}$.

Los brotes son principalmente el resultado de la transmisión de persona a persona de este virus, que se produce a través del contacto directo con el cuerpo, los fluidos corporales (comúnmente a trabajadores de la salud), la ropa contaminada o sábanas de una persona infectada ${ }^{4,5,9,10}$.

Además, se estima que $60 \%$ de los casos del brote actual de Ébola en África se infectaron en los ritos funerarios ${ }^{5}$.

\section{Historia}

Desde su descubrimiento en 1976, en la República Democrática del Congo (ex Zaire), hasta este brote se han producido 24 brotes, con 2.387 casos y letalidades entre 30\% y $90 \%{ }^{5}$.

\section{El brote actual}

En marzo de 2014 se descubrió que el VE era el agente etiológico detrás de un brote de una enfermedad altamente letal que se había iniciado en Guinea en diciembre de 2013. El paciente índice se presume que era un niño de 2 años de edad, del cual se desconoce el mecanismo de infección. Este fue el primer brote conocido del VE en África occidental. Desde ese momento, el brote se ha extendido a una escala nunca antes vista, causando peores epidemias en los países limítrofes de Sierra Leona y Liberia. A medida que el brote ha continuado, se ha exportado el virus a Senegal, Nigeria, Estados Unidos de Norteamérica, España y Mali ${ }^{2,3,11}$.

Las últimas cifras de la Organización Mundial de la Salud (OMS), del 3 de diciembre del 2014, informan que los casos en todo el mundo confirmados y sospechosos eran de 17.145 y han ocurrido 6.070 muertes, con una tasa de letalidad total de $35 \%{ }^{2,12}$. Entre los trabajadores de la salud, un total de 622 han enfermado, de los cuales 346 han fallecido. A causa de esta situación, la OMS ha llevado a cabo una revisión de los equipos de protección personal (EPP) y actualización de las guías para los trabajadores de la salud que prestan atención directa a los pacientes con VE. Además, se considera fundamental para la protección de los trabajadores y los pacientes el entrenamiento obligatorio en el uso de EPP y el manejo clínico, antes de participar en el cuidado de los pacientes ${ }^{12}$.

El blanco del virus son las células endotelia- les, macrófagos, monocitos y los hepatocitos. La infección viral provoca necrosis focal del hígado, órganos linfoides, riñones, testículos y ovarios. Durante la fase aguda, el virus activa múltiples citoquinas implicadas en la patogénesis de la permeabilidad vascular y el shock, además produce una glicoproteína soluble que, se ha especulado, podría interferir con la respuesta inmune normal ${ }^{7}$.

\section{Manifestaciones clínicas}

El período de incubación del brote actual dura un promedio de 9 a 11 días desde el contacto con el virus ${ }^{13}$.

Las manifestaciones clínicas las podemos dividir en 3 fases:

En la Fase I se presentan signos y síntomas iniciales inespecíficos, que pueden aparecer en un rango de 2 a 21 días $^{13}$, pueden incluir fiebre entre 39 y $40 \mathrm{C}^{\circ}$, calofríos, mialgias, cefalea, fatiga y malestar general ${ }^{1,3,13,14}$.

La Fase II es la fase de síntomas viscerales y aparece 2 a 4 días después de la fase I, dura entre 7 y 10 días. Presenta:

\section{Sintomas gastrointestinales:}

Dolor abdominal intenso,náuseas, vómito, diarrea acuosa y deshidratación severa.

\section{Síntomas respiratorios:}

Odinofagia, tos seca y dolor de pecho.

\section{Síntomas hemorrágicos:}

Petequias, inyección conjuntival, epistaxis, hematemesis, melena, hematuria.

\section{Síntomas nerviosos:}

Trastornos de comportamiento (agresividad, confusión, delirio), parestesia, hiperestesia y convulsiones.

\section{Otros:}

Puede observarse abortos espontáneos.

\section{Manifestaciones cutáneas:}

Aparecen entre el $4^{\circ}$ y $5^{\circ}$ día de iniciados los síntomas, estas manifestaciones no amenazan la vida del paciente y se presentan en más de $50 \%$ de los casos. Se pueden observar:

Exantema macular o maculopapular, no pruriginoso, de difícil evaluación en pacientes de raza negra ${ }^{15}$; de características clínicas similar al 
sarampión: lo primero observado son pápulas de color rojo oscuro en torno a las raíces del pelo, en la zona glútea, los brazos, las piernas, la cara, y luego se extiende al tronco y el resto del cuerpo. En algunos casos el exantema se extiende de forma centrípeta de los brazos y las piernas al tronco ${ }^{14}$, luego ocurre la descamación que puede durar hasta 2 semanas y es principalmente en palmas, plantas y extremidades ${ }^{16,17}$.

Compromiso de mucosa en los ojos, boca y faringe; $50 \%$ de los pacientes tienen congestión conjuntival bilateral con fotofobia, pueden presentar gingivitis, glositis y en el paladar pequeñas lesiones claras blanquecinas parecidas a "gránulos de tapioca" 14,18 .

Fase III: Aquí ocurre la recuperación o muerte.

$\mathrm{Si}$ aparece taquipnea, singulto o anuria, son signos de mal pronóstico y la muerte se produce después de 2 a 3 días, en promedio ${ }^{3,14,18}$.

Los sobrevivientes experimentan un largo período (un mes o más) de convalecencia dolorosa con fatiga intensa, pérdida del apetito, profunda postración, pérdida de peso y artralgias migratorias.

Las secuelas puede incluir orquitis, hepatitis recurrente, mielitis transversa y uveítis, confusión, ansiedad y comportamiento inquieto y agresivo.

Los signos y síntomas más comunes en pacientes de África occidental durante el actual brote incluyen: fiebre (87\%), fatiga (76\%), vómitos (68\%), diarrea $(66 \%)$ y pérdida del apetito $(65 \%)^{13}$.

Los pacientes con enfermedad mortal, por lo general, desarrollan signos clínicos más severos durante la infección temprana y mueren entre los días 6 y 16 de complicaciones tales como falla multiorgánica y shock séptico (media de 7,5 días a partir de la aparición de los síntomas).

En los casos no fatales, los pacientes pueden tener fiebre por varios días y mejorar, por lo general alrededor del día $6^{013}$.

La causa de muerte en los países con pocos recursos en los que se han producido brotes a menudo es la deshidratación y el desequilibrio electrolítico ${ }^{3}$.

\section{Hallazgos de laboratorio $^{1}$}

\section{Leucopenia}

Es seguida por un recuento de neutrófilos elevado, granulocitos inmaduros y linfocitos anormales.

\section{Trombocitopenia}

Recuentos de plaquetas son por lo general en el intervalo de 50.000 a $100.000 / \mu \mathrm{L}$. Este recuento por lo general llega a su punto más bajo alrededor de 6 a 8 días de la enfermedad.

\section{Elevación de las transaminasas}

El virus pude causar necrosis hepática multifocal, las pruebas de química de sangre por lo general demuestran aminotransferasas (GOT y GPT) elevadas.

\section{Anomalías de coagulación}

Protrombina (PT) y tiempo de tromboplastina parcial (PTT) se prolongan y productos de degradación de fibrina aumentan.

\section{Alteraciones renales e hidroelectroliticas}

Proteinuria, elevación de creatinina, hiponatremia e hipokalemia. En el curso de la enfermedad, un alto porcentaje de pacientes termina presentando un cuadro de fracaso renal agudo (FRA) en distinto grado. La etiología de este FRA es multifactorial. Por un lado, el cuadro clínico de vómitos y diarreas masivos causan un estado de hipovolemia, a lo que se suma una significativa respuesta inflamatoria a la infección, que condiciona un incremento en la permeabilidad capilar y descenso en la albúmina sérica, que a su vez conduce a la depleción del volumen plasmático efectivo de forma similar a cualquier otro cuadro séptico. A este escenario se suman las alteraciones en la coagulación que presentan estos pacientes, que favorecen tanto la diátesis hemorrágica como la aparición de un cuadro de coagulación intravascular diseminada o microangiopatía trombótica asociada a la consiguiente afectación renal. Además, el virus puede infectar células tubulares y causar daño histológico directo, contribuyendo todos estos factores a la instauración del cuadro de FRA.

La aparición de FRA es un factor determinante de mal pronóstico en estos pacientes, lo que hay que tener en cuenta a la hora de asistirles ${ }^{19}$.

\section{Diagnóstico diferencial}

Los primeros síntomas pueden simular una gripe, malaria, fiebre tifoidea, hepatitis fulminante, sepsis, salmonelosis no tífica, varias formas de encefalitis, fiebre del dengue, fiebre amarilla, 
fiebre de Lassa, Marburg y otras enfermedades hemorrágicas. Los síntomas hemorrágicos se pueden confundir con leucemia aguda, lupus eritematoso, púrpura trombocitopénico trombótico o idiopático, y el síndrome urémico hemolítico, entre otros ${ }^{20}$.

\section{Diagnóstico}

Descartar los diagnósticos diferenciales antes descritos.

Se pueden realizar los siguientes exámenes: ELISA; pruebas de detección de antígenos; prueba de seroneutralización; reacción en cadena de la polimerasa con transcriptasa inversa (RT-PCR) (disponible en Chile) $)^{5}$; y aislamiento del virus mediante cultivo celular ${ }^{3,4}$.

Las muestras de los pacientes suponen un enorme peligro biológico, y las pruebas tienen que realizarse en condiciones de máxima contención biológica. Se deben tomar al tercer día de iniciada la sintomatología, y el traslado de la muestra debe realizarse con "triple embalaje"

\section{Manejo de pacientes con Ébola}

Primero es la definición de casos.

Caso sospechoso: Debe cumplir los criterios clínicos y epidemiológicos

Criterios clínicos: Fiebre, más alguno de los siguientes síntomas: cefalea, mialgias, artralgias, vómitos, diarrea, dolor abdominal o hemorragias.

Criterios epidemiológicos: Viaje dentro de los últimos 21 días a áreas endémicas o contacto con caso sospechoso o confirmado.

\section{Caso confirmado}

Debe cumplir los criterios clínicos, los criterios epidemiológicos y una PCR positiva.

Todo caso sospechoso se debe notificar inmediatamente a la Secretaria Regional Ministerial de Salud (SEREMI) local correspondiente y programar el traslado a centros de referencia nacional. En Chile se definieron 5 centros:

Hospital Regional de Antofagasta, Hospital Naval de Viña del Mar, Hospital Lucio Córdoba, Hospital Militar y Hospital Regional de Magallanes ${ }^{5}$.

En los centros asistenciales, deben estar determinadas las áreas que serán aisladas y utilizadas para este efecto. Se debe realizar un aislamiento de contacto y gotitas, además de enseñar al personal médico el uso del EPP del VE.

El VE tiene la capacidad de sobrevivir en el ambiente un número no precisado de días, estimándose en unos 10. Tanto los ambientes en que el paciente estuvo, como las ropas y objetos que usó tienen riesgo de estar contaminados y, por ende, ser una fuente de infección. Es por este motivo que se requiere controlar esas posibles fuentes de contagio para prevenir casos secundarios. La limpieza de los lugares y ambientes se debe realizar con una solución de hipoclorito de sodio en dilución de 1.000 ppm.

En caso de muerte, las autopsias no son recomendables y deben realizarse solo si es estrictamente necesario. El protocolo señala que el cuerpo debe ser colocado en una bolsa plástica impermeable y sellada (bolsas de aislamiento resistente a la filtración de líquidos, bolsas mortuorias) y luego en un ataúd sellado, para evitar así futuros contagios.

\section{Tratamiento}

El tratamiento es de soporte, principalmente se trata con hidratación endovenosa para evitar el shock. En el pasado, las tasas de mortalidad han superado $50 \%$ y han alcanzado $90 \%$; actualmente la tasa de letalidad es de $35 \% \%^{7,21}$.

No hay vacunas contra la VE. Se están probando varias, pero ninguna está aún disponible para uso clínico ${ }^{4}$.

\section{Conclusión}

El VE es un virus altamente contagioso y de alta mortalidad. El contagio es a través de fluidos, contacto con objetos infectados y animales portadores.

Las manifestaciones mucocutáneas de EV son frecuentes, no específicas y no amenazan la vida. Por lo general, se producen entre el $2^{\circ}$ y $7^{\circ}$ día después de la aparición inicial de síntomas y pueden estar presentes durante la convalecencia.

Es importante conocer las normas de manejo en caso de existir un caso sospechoso.

No está disponible una terapia específica aprobada para el tratamiento de esta enfermedad. 


\section{Referencias}

1. Mike Bray. Epidemiology, pathogenesis and clinical manifestation of Ebola and Marburg virus disease [Internet] UptodateNoviembre 2014.

2. Ministerio de Salud Chile . Informe de Situación de Enfermedad por virus del Ebola. Diciembre 2014 [Internet] .[Consultado el 4 de Diciembre 2014]

3. Toner E, Adalja A, Inglesby T. A Primer on Ebola for Clinicians. Disaster Med Public Health Prep 2014; 1-5.

4. OMS. Enfermedad por el virus del Ebola. [Internet] [Consultado el 10 de Noviembre de 2014].

5. Ministerio de Salud Chile. Plan de contingencia para enfrentamiento de casos de Enfermedad por Virus Ebola en Chile. Sep 2014; [ Internet] [Consultado el 12 de noviembre 2014].

6. Kohl C, Kurth A. European Bats as Carriers of Viruses with Zoonotic Potential. Viruses 2014; 6 (8): 3110-28.

7. Weir E. Ebola erupts again. Can Med Assoc J 2001; 164 (5): 685 .

8. Marsh GA, Haining J, Robinson J, Foord A, Yamada M, Barr J, et al. Ebola Reston virus infection of pigs: clinical significance and transmission potential. J Infect Dis 2011; 204: 804-9.

9. MacNeil A, Rollin PE. Ebola and Marburg Hemorrhagic Fevers: Neglected Tropical Diseases? PLoS Negl Trop Dis $2012 ; 6$ (6).

10. OMS. Lo que sabemos de la transmisión del virus del Ebola entre humanos [Internet] [Consultado el 10 de noviembre de 2014].

11. Joffe S. Evaluating novel therapies during the Ebola epidemic. JAMA 2014; 312: 1299-300.

12. WHO. Ebola response roadmap situation report update 3 diciembre 2014. [Internet]. [Consultado el 4 de diciembre de 2014].

13. Center for Disease Control and Prevention. Ebola virus disease Information for Clinicians in U.S. Healthcare Settings [Internet]. [Consultado el 28 de octubre de 2014].

14. Nkoghe D, Leroy EM, Toung-Mve M, González JP. Cutaneous manifestations of filovirus infections. Int J Dermatol 2012; 51 (9): 1037-43.

15. Ebola haemorrhagic fever in Sudan, 1976. Bull World Health Organ 1978; 56 (2): 247-70.

16. Ebola haemorrhagic fever in Zaire, 1976. Bull World Health Organ 1978; 56 (2): 271-93.

17. Tyring SK, Yen-Moore A, Azar DT, Koch DD. Mucocutaneous Manifestations of Viral Diseases. CRC Press; 2002. 583 p.

18. Bwaka MA, Bonnet M-J, Calain P, Colebunders R, De Roo A, Guimard Y, et al. Ebola hemorrhagic fever in Kikwit, Democratic Republic of the Congo: clinical observations in 103 patients. J Infect Dis 1999; 179 (Supplement 1): S1-7.

19. Sociedad española de nefrología. Documento ébola. 2015 ; [Internet] [Consultado el 25 de junio del 2015].

20. Casillas AM, Nyamathi AM, Sosa A, Wilder CL, Sands H. A current review of Ebola virus: pathogenesis, clinical presentation, and diagnostic assessment. Biol Res Nurs. 2003; 4 (4): 268-75.

20. Clark DV, Jahrling PB, Lawler JV. Clinical Management of Filovirus-Infected Patients. Viruses 2012; 4 (12): 1668-86. 